\title{
Evaluation of turbine microjet engine operating parameters in conditions conducive to inlet freezing
}

\author{
Jaroslaw Markowski ${ }^{1, *}$, Damian Olejniczak ${ }^{1}$, and Pawel Wirkowski ${ }^{2}$ \\ ${ }^{1}$ Poznan University of Technology, Faculty of Machines and Transport, ul. Piotrowo 3, 60-965 Poznan, Poland \\ ${ }^{2}$ Polish Naval University, Faculty of Mechanical and Electrical Engineering, ul. Smidowicza 69, 81-127 Gdynia, Poland
}

\begin{abstract}
The problem of turbine microjet engine operation is related to flight conditions of unmanned aircraft. These flights are often performed at low altitudes, where, in autumn and winter conditions, the air can be characterized by high humidity and low temperature. Such operating conditions may cause freezing the turbine engine inlet. In particular, this problem may be related to microengines, which most often are not equipped with a de-icing installation. Frosting of the inlet violates the air flow conditions at the engine inlet and may cause unstable operation and even outages, which eventually may lead to a loss of aircraft's stability and breakdown. Therefore, an attempt was made to evaluate the changes in operational parameters of the turbine microjet engine under conditions leading to the freezing of the inlet. The engine test was performed in stationary conditions and the analysis of the obtained results are presented in this article.
\end{abstract}

\section{Introduction}

The process of converting the state of water contained by the air in the form of steam into a solid form accumulating on the elements of the aircraft structure during flight is called icing. The occurrence of aircraft icing is a phenomenon that adversely affects the volatility of the aircraft. It changes the wing profile and increases the weight of aircraft [1-3]. Icing depends on many factors and occurs under favorable weather conditions such as high humidity and low temperature. The atmospheric conditions conducive to the icing of the inlet system of the turbine engine are:

- low dew point temperature,

- high air humidity,

- presence of water in the atmosphere in all forms, especially in the form of clouds, precipitation, overflowing water,

- air temperature less than $10^{\circ} \mathrm{C}$.

The icing of the turbine engine inlet system is particularly undesirable because of the negative effects on engine performance. It narrows the cross section of the engine intake duct, which translates into a decrease in the mass of the flowing medium, and consequently results in reduced engine thrust $[4,5]$. Icing of individual components of the turbine engine compressor can cause undesired blade vibration and deterioration of the fluid flow conditions in the interstitial space. The icing of the turbine engine's inlet can cause a power loss of up to $40 \%$ of the rated power and even lead to the motor compressor stall. In extreme cases it may turn off the flame in the combustion chamber or permanently damage the engine.
The location of the ice layer in the inlet system of the turbine engine depends on the size of the water molecules contained in the air and on the type of construction of the element located in the airflow zone. Small molecules of water are icing single protruding elements of the inlet system. These include temperature and air pressure measuring elements placed in the inlet for controlling the engine systems. Due to the operation of airplanes under the conditions of icing, the pressure measurement elements in the engine inlet and the hull of the aircraft used for determining the flight velocity are continuously heated to prevent the freezing of these components and thus losing basic flight parameters. On the other hand, during freezing rain or high-watered clouds, icing already occurs at the edge of the inlet of turbine engine, on the walls of intake duct, the cap, inlet wrenches of compressor steering wheel. This type of icing is intense and can destabilize the engine.

The accumulation of ice on the turbine engines inlet causes diameter reduction of the engine air inlet, aggravating the airflow conditions, which results in the deterioration of engine performance. The basic problem is the reduction of engine thrust value. String is a basic parameter characterizing a jet engine. By adopting a onedimensional thermodynamic thermoform model, the engine sequence can be defined as the difference in the flow rate of the medium at the inlet and outlet of the jet engine. The icing of turbine engine air inlet leads to reduction in the air mass flow rate, by narrowing the inlet flow channel and thereby reducing the value of the thrust generated. A single-turbine engine sequence is represented by the dependence (1). 


$$
F_{c}=\dot{m}\left[(1+\tau) C_{5}-V_{H}\right]
$$

where:

$F_{c}$ - engine thrust value $[\mathrm{N}]$,

$\dot{m}$ - mass flow rate of the medium $[\mathrm{kg} / \mathrm{s}]$,

$\tau$ - percentage of fuel relative to airflow [\%],

$C_{5}-$ speed at the engine outlet $[\mathrm{m} / \mathrm{s}]$,

$V_{H}-$ speed at the inlet to the engine $[\mathrm{m} / \mathrm{s}]$.

The icing of inlet systems is a particular problem for the operation of engines without de-icing systems. Undoubtedly, aircrafts equipped with turbine engines without anti-icing installations include unmanned aerial vehicles. An unmanned aircraft equipped with a turbine engine, which for structural reasons is devoid of antiicing installations, is exposed to icing of the intake system. Therefore, the problem of safe use of turbinepowered unmanned aerial vehicles in autumn-winter and winter-spring periods is emerging. Unmanned aerial vehicles, depending on their purpose, fly at low altitude during most of their operating hours, where during this period the air is characterized by high humidity and low temperatures. Therefore, in order to evaluate changes in micro engine turbine parameters, a stationary test was performed on selected turbine microengine under conditions conducive to freezing of the inlet.

\section{Methodology}

The object of the stationary test was the GTM-120 turbine engine (Fig. 1). It is a single-flow engine, with single-stage radial compressor, annular combustion chamber and single-stage axial turbine. The stationary test and measurement station consists of additional pneumatic starter system and electronic control and data recording system for the GTM-120 engine [6-8]. Fuel consumption was measured using a fuel gauge operating according to the gravimetric method. Measurement of the thrust value was made by the KMM20-200N force sensor. In order to assess the temperature distribution of the inlet of the turbine engine during the test, a thermal imaging camera was used. To simulate precipitation conditions that increase air humidity within the engine inlet, a spray nozzle for water supplied from the water supply was used. The air temperature at the time of the test was $t_{\mathrm{ot}}=-2{ }^{\circ} \mathrm{C}$, atmospheric pressure $p_{\mathrm{ot}}=1025 \mathrm{hPa}$.

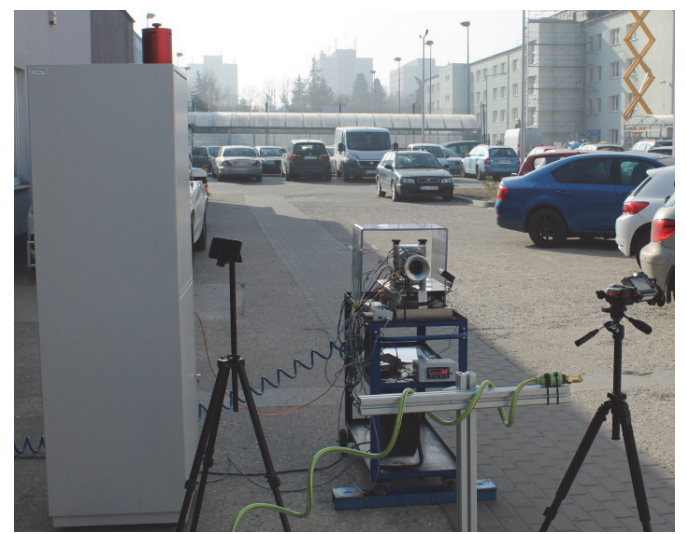

Fig. 1. The view of a test bench during a stationary test of the GTM-120.
The research test was divided into two phases. In the first stage the speed characteristics of the full-range engine operating at ambient conditions were recorded. Measurements of operating parameters were made for the set thrust in the minimum stroke range of approximately $F_{c}=15 \mathrm{~N}$, then $F_{c}=20 \mathrm{~N}$, subsequent set points with $10 \mathrm{~N}$ step incrementally increasing the engine sequence to a maximum value of $F_{c}=130 \mathrm{~N}$.

The second stage of the study consisted of evaluating changes in engine operating parameters caused by changes in ambient conditions by spraying water in the vicinity of the engine inlet. These tests were performed for the selected operating range corresponding to the set point of the thrust force $F_{c}=90-130 \mathrm{~N}$. This is a range of $70-100 \%$ of the maximum thrust. This value selection was based on the experience of studies and data available in the literature $[6,7]$, which indicate the value of the turbine engine load as the load most likely to occur during engine operation.

After setting the engine parameters for the resulting thrust value $F_{c}=90 \mathrm{~N}$, the water was sprayed at a distance of about $700 \mathrm{~mm}$ from the engine inlet. The distance of the spray nozzle relative to the inlet was determined by the direction and speed of the wind so as to provide a mist of water sprayed by the engine before the inlet (Fig. 2). The test was performed until the dynamic pressure measuring tube in the engine inlet was frozen. The measuring instrument allowed registration the operating parameters of the engine with frequency of $1 \mathrm{~Hz}$. Fuel consumption was recorded at fixed engine operating points as averaged over a 5 second period. Registered data was analyzed.

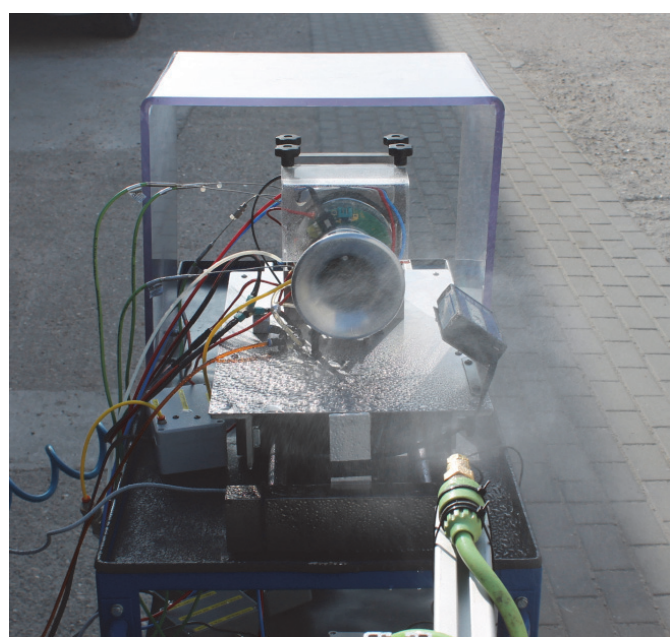

Fig. 2. The view of the GTM-120 stationary test during spraying water before engine inlet, $t_{\mathrm{ot}}=-2{ }^{\circ} \mathrm{C}, p_{\mathrm{ot}}=1025 \mathrm{hPa}$.

\section{Analysis of the results}

During the tests basic operating parameters were determined at ambient conditions at air temperature $t_{\mathrm{ot}}=$ $=-2{ }^{\circ} \mathrm{C}$, atmospheric pressure $p_{\mathrm{ot}}=1025 \mathrm{hPa}$. For these conditions the engine characteristics have been determined, showing the dependence of the measured parameters: $T_{1}-$ air temperature at the engine inlet $[\mathrm{K}]$, $T_{2}$ - air temperature behind the compressor $[\mathrm{K}], T_{3}-$ 
temperature behind the combustion chamber $[\mathrm{K}], T_{4}-$ exhaust temperature in the exhaust nozzle $[\mathrm{K}] ; p_{c}-$ preturbine pressure $[\mathrm{kPa}], G_{e}-$ fuel consumption $[\mathrm{g} / \mathrm{s}]$, as a function of thrust $F_{c}$. The waveforms of individual parameters as a function of thrust are shown in graphical form (Fig. 3-5).

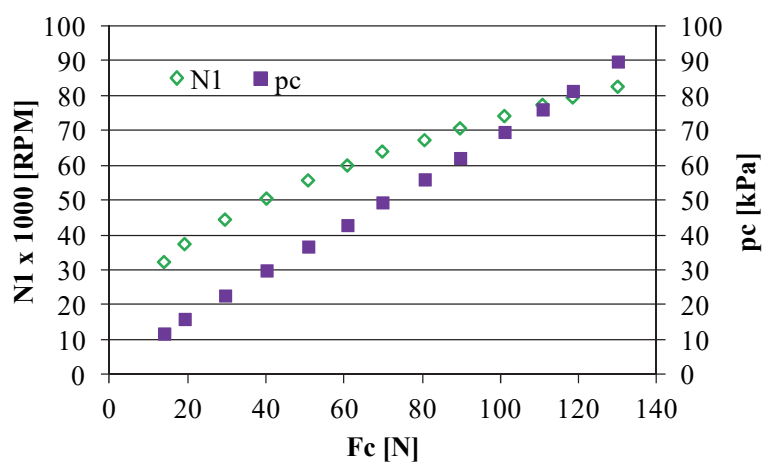

Fig. 3. GTM-120 engine shaft speed and pre-turbine pressure as a function of thrust under ambient conditions.

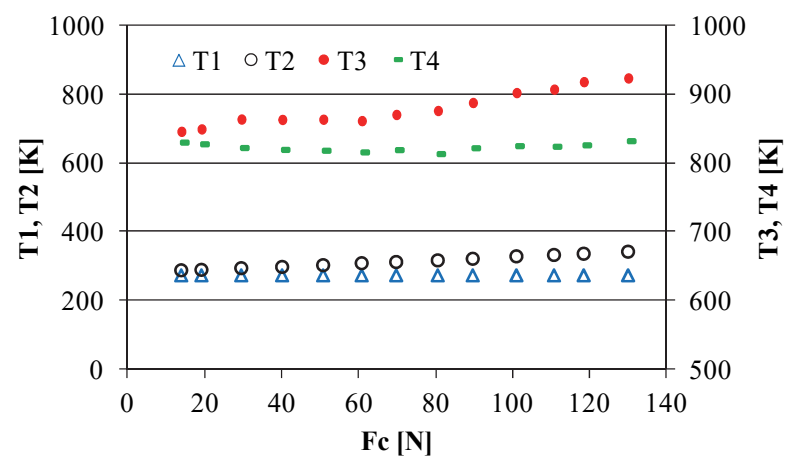

Fig. 4. The temperature values at the individual measuring points of the GTM-120 engine as a function of thrust under ambient conditions.

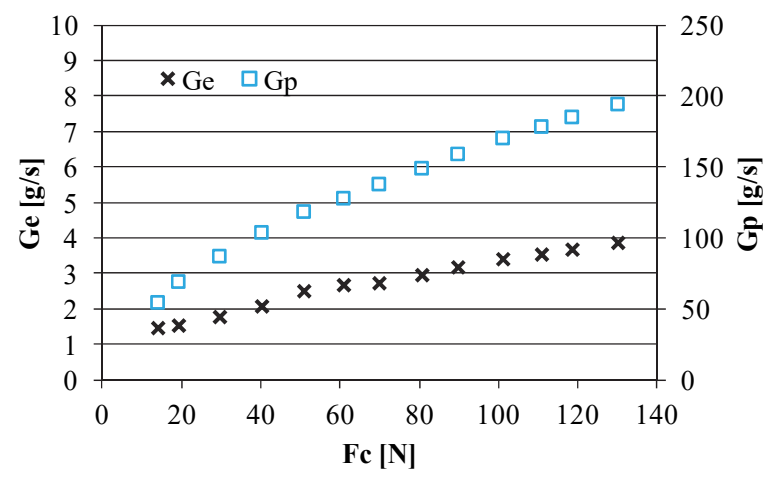

Fig. 5. Fuel consumption and air consumption as a function of thrust under ambient conditions.

Presented characteristics refer to changes in engine operating parameters provided in the second stage of the test, during which water was sprayed before the engine's inlet. The study was conducted for four thrust values. The first set of thrust was $F_{c}=90 \mathrm{~N}$. During the operation of the engine with a set thrust value, the spray nozzle was positioned in the space before the engine inlet. Correction of the thrust set was made and measurements were conducted. In the following steps, thrust values were changed and operating parameters were measured. Registered changes of individual operating parameters were applied to the characteristics obtained during the first stage of the test (Fig. 6-8).

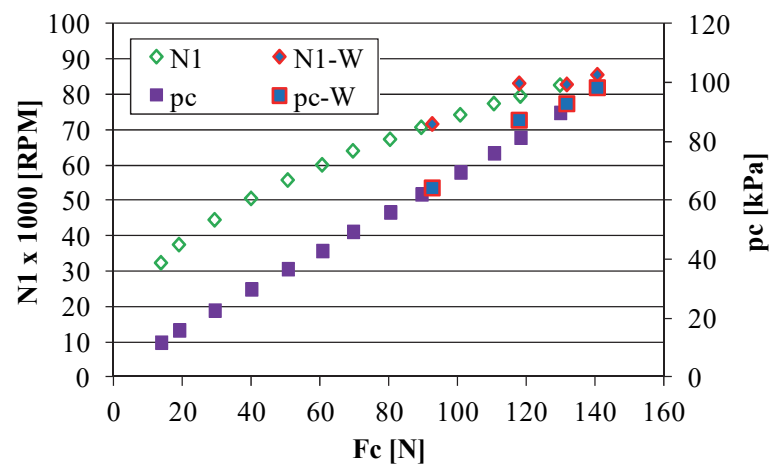

Fig. 6. GTM-120 engine shaft speed and pre-turbine pressure as a function of thrust with applied values obtained by spraying water, under ambient conditions.

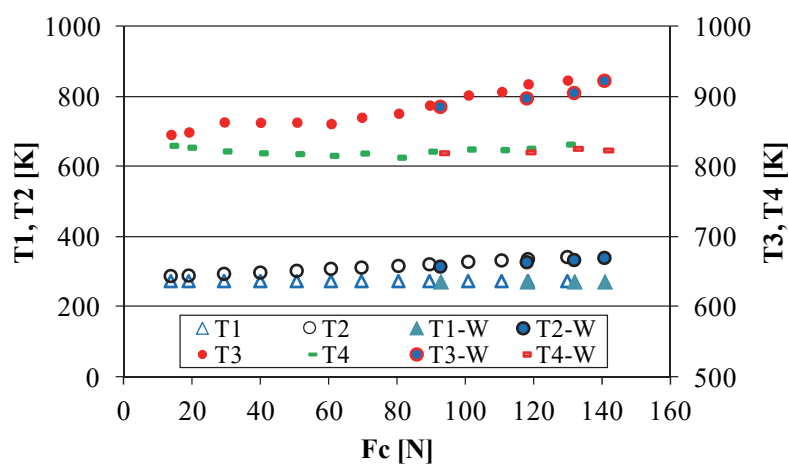

Fig. 7. The temperature values at the individual measuring points of the GTM-120 engine as a function of the thrust force with the applied values obtained when spraying water, under ambient conditions.

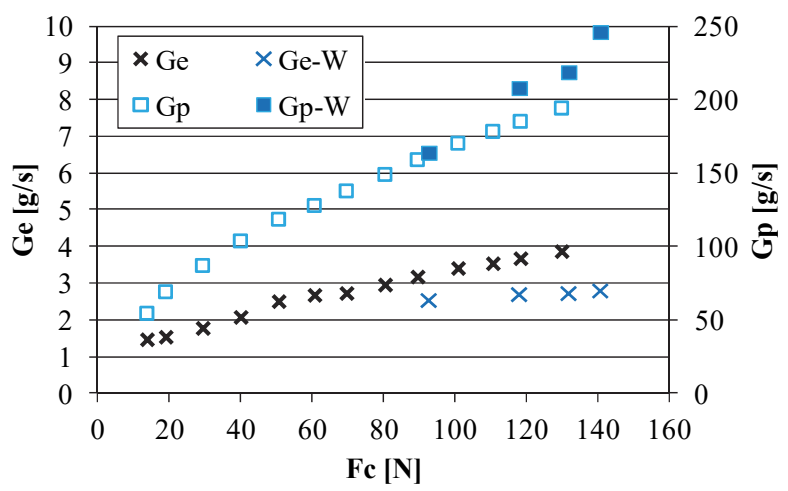

Fig. 8. Fuel consumption and air consumption as a function of thrust for GTM-120 engine with the values obtained when spraying water, under ambient conditions.

Comparative assessment of operating parameters obtained in the first and second stage of the test indicates that the spraying of water before the inlet of the turbine engine does not cause significant changes in the rotational speed of the motor shaft $\mathrm{N} 1$ and the pressure 
of the medium before the turbine $\mathrm{p}_{\mathrm{c}}$. It also does not significantly affect the temperature at the inlet of the engine $T_{1}$, the temperature behind the compressor $T_{2}$, the temperature before the turbine $T_{3}$. This results in a decrease in the flue gas temperature in the engine exhaust nozzle by approximately $20 \mathrm{~K}$. The changes in air parameters caused by the spray of water resulted in an increase of air flow and engine thrust while fuel consumption $G_{p}$ decreased. Airflow increased by approximately $10 \%$ and fuel consumption $\mathrm{G}_{\mathrm{e}}$ reduced by approximately $28 \%$.

During the tests temperature measurements were made on the inner surface of the engine inlet with the use of a thermal camera. The engine inlet image was recorded under conditions set for the thrust setting point of $F_{c}=90 \mathrm{~N}$, without water spray (Fig. 9), and during engine operation with the same thrust setting with water spraying in space before engine air inlet. (Fig. 10).

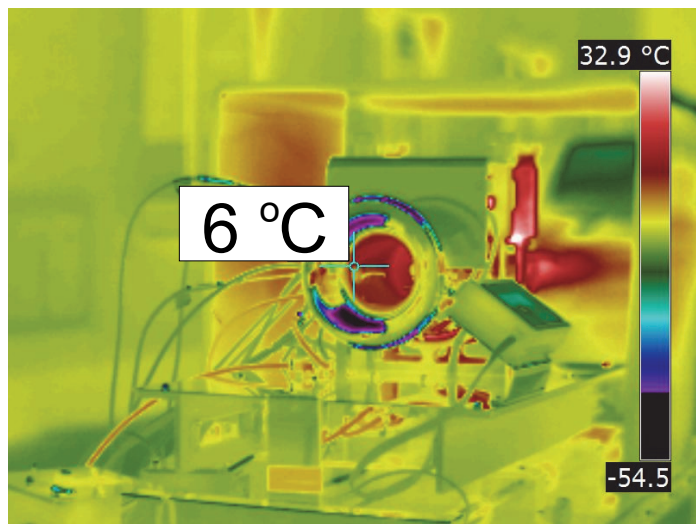

Fig. 9. Thermal distribution of the engine (inlet) operating in ambient conditions with thrust $F_{c}=90 \mathrm{~N}$.

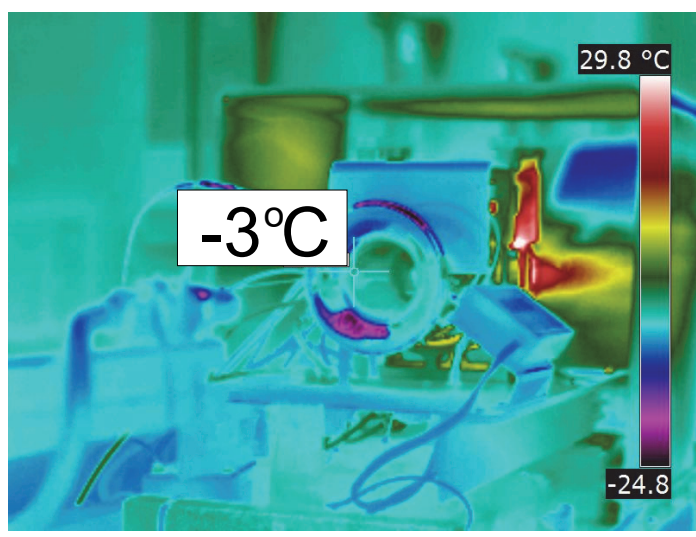

Fig. 10. Thermal distribution of the engine (inlet) with thrust of $F_{c}=90 \mathrm{~N}$, while spraying water in space before inlet.

The analysis of the thermal distribution shows the difference in temperature at the inlet of the engine measured at the same point. The surface temperature at the inlet of the engine with a thrust of $F_{c}=90 \mathrm{~N}$, without spray of water was $6{ }^{\circ} \mathrm{C}$, and when the water was sprayed at the inlet area, the surface of the inlet at the measuring point was $-3{ }^{\circ} \mathrm{C}$. Consequently, the change in the air space before the air inlet at the ambient temperature $t_{\mathrm{ot}}=-2{ }^{\circ} \mathrm{C}$ and the ambient pressure $p_{\mathrm{ot}}=$ $=1025 \mathrm{hPa}$ causes a drop by $9{ }^{\circ} \mathrm{C}$. Such change in the surface temperature of the engine inlet caused water droplets freezing settling on the inlet edge and on the dynamic pressure measuring elements positioned inside of the inlet (Fig. 11). It should be emphasized that the interior surface of the engine air inlet during the test did not overlap with ice.

The study was stopped when a layer of ice appeared on the dynamic pressure probe. The possibility of engine damage by the ice layer, forced to stop the measurements.

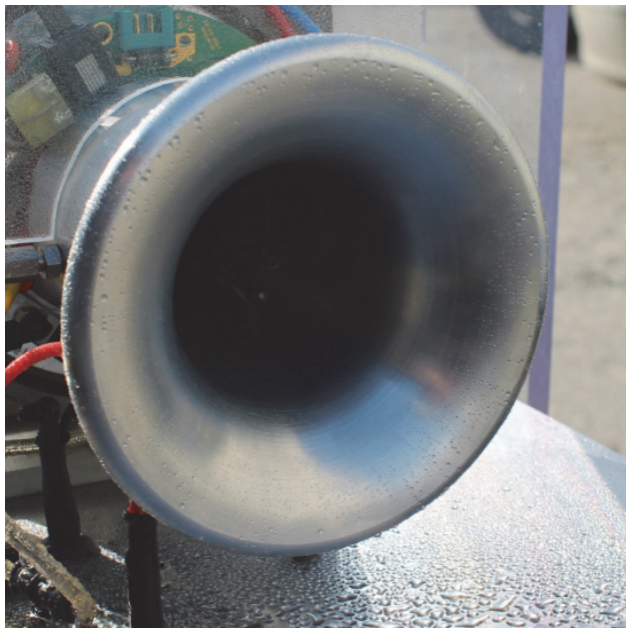

Fig. 11. The view of the GTM-120 inlet after tests.

\section{Conclusions}

The micro turbine engine tests conducted at ambient conditions with an air temperature of $t_{\mathrm{ot}}=-2{ }^{\circ} \mathrm{C}$ and $p_{\text {ot }}=1025 \mathrm{hPa}$, and an analysis of the obtained results, allowed to make a few conclusions. The spraying of water in the space before the air inlet of the turbine engine under ambient conditions does not cause significant changes in the temperature of the refrigerant behind the compressor and before the engine turbine. Also, there were no significant change in the pre-turbine pressure and engine shaft speed. However, it increases the mass flowing factor by about $10 \%$. The medium mass increase according to equation (1) results in an increase in thrust. In the case of tests conducted in relation to thrust level, the increase in the mass of the flowing medium contributes to the reduction of fuel consumption. Reduction in fuel consumption was about $28 \%$. Reducing fuel consumption has also contributed to reducing exhaust gas temperature at the engine outlet. Changes in these parameters confirm the theoretical dependence of the turbine engines.

The comparative analysis of changes in inlet surface temperature during operation showed that the surface temperature of the inlet at the point of measurement could be reduced by $9{ }^{\circ} \mathrm{C}$ under ambient conditions due to spraying of water in the inlet area, which may cause the engine inlet to freeze.

The study additionally indicated that the inlet temperature of the engine just before the compressor is positive. The reason for this is the compact design of the engine, which provides the inlet heat from the 
compressor housing. This situation causes the turbine engine of such a design to have a high resistance to freezing without additional intake heating systems.

The study presented in this article was performed within the statutory research (contract No. 05/52/DSPB/0244).

\section{References}

1. R. Chachurski, P. Waślicki, Instalacje przeciwoblodzeniowe $i$ odladzające statków powietrznych (WAT, 2011)

2. R. Chachurski, P. Waślicki, Wykrywanie $i$ sygnalizacja oblodzenia statków powietrznych (WAT, 2011)

3. R. Chachurski, Zagrożenia oblodzeniem lotniczych silników ttokowych (WAT, 2011)

4. A. Gębura, K. Janusiak, M. Poradowski, Journal of Konbin (2014)

5. A. Milkiewicz, R. Stepaniuk, Praktyczna aerodynamika $i$ mechanika lotu samolotu odrzutowego, $w$ tym wysokomanewrowego (Warszawa, 2009)

6. J. Merkisz, J. Pielecha, S. Radzimirski, Springer Tracts on Transportation and Traffic 4, 67-90 (2014), DOI: 10.1007/978-3-319-02705-0_4

7. J. Merkisz, J. Markowski, J. Pielecha, Selected Issues in Exhaust Emissions from Aviation Engines (Nova Science Publishers, 2014)

8. J. Merkisz, J. Markowski, J. Pielecha, D. Karpinski, M. Galant, 18 ETH-Conference on Combustion Generated Nanoparticles (Zurich, 2014) 